Check for updates

Cite this: Sustainable Energy Fuels, 2019, 3, 1225

Received 16th January 2019 Accepted 11th March 2019

DOI: $10.1039 / c 9 s e 00024 k$

rsc.li/sustainable-energy

\section{Protecting effect of mass transport during electrochemical reduction of oxygenated carbon dioxide feedstocks $\uparrow$}

\author{
Kindle Williams, (D) Nathan Corbin, (D) Joy Zeng, (D) Nikifar Lazouski, (D) \\ Deng-Tao Yang (D) and Karthish Manthiram (iD *
}

\begin{abstract}
Electrochemical $\mathrm{CO}_{2}$ reduction is a promising path toward mitigating carbon emissions while also monetizing waste gas through chemicals production and storage of surplus renewable energy. However, deploying such a technology for use on industrial $\mathrm{CO}_{2}$ sources requires an understanding of the effects that gas feed impurities have upon $\mathrm{CO}_{2}$ reduction reaction $\left(\mathrm{CO}_{2} \mathrm{RR}\right)$. In this work, we elucidate the impact of molecular oxygen on the network of reactions occurring in a $\mathrm{CO}_{2}$ reduction system. Our findings indicate that for a planar, polycrystalline $\mathrm{Au}$ electrode in an aqueous environment, oxygen reduction current is limited by the transport characteristics specific to the cell geometry and solvent; as a result, mass transport confers a protective effect by mitigating the otherwise thermodynamically and kinetically favorable reduction of oxygen. The presence of oxygen does not appear to have a significant impact on either $\mathrm{CO}_{2} \mathrm{RR}$ or hydrogen evolution partial currents, indicating that the mechanisms of reduction reactions involving oxygen are independent of $\mathrm{CO}_{2} \mathrm{RR}$ and hydrogen evolution. Further, an electrokinetic mechanistic analysis indicates many feasible candidates for the rate-determining step of $\mathrm{CO}_{2} \mathrm{RR}$; there is no indication that the $\mathrm{CO}_{2} \mathrm{RR}$ mechanism at $P_{\mathrm{CO}_{2}}=0.5 \mathrm{~atm}$ is altered by the presence of oxygen, as the Tafel slopes $\left(59 \mathrm{mV} \mathrm{dec}{ }^{-1}\right.$ ) and reaction orders with respect to bicarbonate (0), $\mathrm{CO}_{2}$ $(\sim 1.5)$, and protons ( 0 from lack of KIE) are consistent between systems with $P_{\mathrm{O}_{2}}=0$ atm and those with $P_{\mathrm{O}_{2}}=0.5 \mathrm{~atm}$. While this is promising for the robustness of $\mathrm{CO}_{2} \mathrm{RR}$ to oxygen impurities in gas feeds, the ultimate design tradeoff when utilizing $\mathrm{CO}_{2}$ sources containing oxygen is between the cost of separation processes and the corresponding cost of power inefficiency as a result of electrons lost to oxygen reduction. This represents a first step in understanding kinetic and transport considerations in the design of gas-impurity-tolerant $\mathrm{CO}_{2}$ reduction systems.
\end{abstract}

\section{Introduction}

With the rise of concern regarding carbon dioxide $\left(\mathrm{CO}_{2}\right)$ emissions, $\mathrm{CO}_{2}$ valorization as a means of energy storage or chemicals production is an attractive pursuit. While round-trip efficiencies for energy storage technologies such as lithium ion batteries and pumped hydro power are greater than those for $\mathrm{CO}_{2}$ electroreduction to fuels, ${ }^{1}$ the generation of energy-dense chemicals allows for flexibility of energy recovery strategy as well as for product utilization in synthetic organic applications. $\mathrm{CO}_{2}$ reduction reactions $\left(\mathrm{CO}_{2} \mathrm{RR}\right)$ have been employed to reach products ranging from carbon monoxide ( $\mathrm{CO}$ ) and formate to more deeply-reduced products such as ethylene, methanol, and ethanol. ${ }^{2-4}$ Generating such products from point sources of $\mathrm{CO}_{2}$

Department of Chemical Engineering, Massachusetts Institute of Technology, Cambridge, MA 02139, USA. E-mail: karthish@mit.edu

$\dagger$ Electronic supplementary information (ESI) available: In-depth materials \& methods, discussion re: effects of $\mathrm{O}_{2}$ at lower overpotentials, transient current decay phenomena, and kinetic rate law derivations. See DOI: 10.1039/c9se00024k may prove to be an attractive means of both curtailing and monetizing $\mathrm{CO}_{2}$ emissions in the future.

A major limitation of existing studies of $\mathrm{CO}_{2}$ electroreduction, however, is that almost all experiments conducted to date have utilized gas feeds of $99.9 \%$ or purer $\mathrm{CO}_{2}$. Those investigations which have focused on dilute streams of $\mathrm{CO}_{2}$ have so far mostly done so in the context of low-conversion molecular catalysts and inert gas impurities such as nitrogen $\left(\mathrm{N}_{2}\right) \cdot{ }^{5}$ If $\mathrm{CO}_{2}$ reduction is ever to be practically employed, it may not be feasible - logistically or economically - to expect endusers of $\mathrm{CO}_{2}$ reduction technology to supply feedstocks of high $\mathrm{CO}_{2}$ purity. Some estimates have indicated that the purification of $\mathrm{CO}_{2}$ from air (which currently contains $\sim 400 \mathrm{ppm}$ or $\left.0.04 \% \mathrm{CO}_{2}\right)^{6}$ would cost roughly $\$ 1000$ per metric ton $\mathrm{CO}_{2}$ captured, while similar capture from the effluents of coal-fired power plants (containing 10-15\% $\mathrm{CO}_{2}$ ) would cost about \$25100 per metric ton $\mathrm{CO}_{2}{ }^{7}$ A more promising study on the design of a system for direct $\mathrm{CO}_{2}$ capture from air was able to decrease the cost of air capture to $\$ 94-232$ per ton $\mathrm{CO}_{2} \cdot{ }^{8}$ However, even this cost may prove prohibitive for the commercialization of 
$\mathrm{CO}_{2}$ reduction technology, as many technoeconomic analyses investigating $\mathrm{CO}_{2}$ reduction viability rely on $\mathrm{CO}_{2}$ capture costs being no more than $\$ 30-60$ per ton $\mathrm{CO}_{2}{ }^{9,10}$ Therefore, it would be valuable for developed $\mathrm{CO}_{2}$ reduction technologies to exhibit some degree of tolerance to gas feed impurities.

Previous studies involving non-inert impurities in $\mathrm{CO}_{2}$ reduction streams have focused on the effects of $\mathrm{NO}_{x}, \mathrm{SO}_{x}$, and $\mathrm{O}_{2}$ on $\mathrm{CO}_{2} \mathrm{RR}$ at $\mathrm{Cu}$ cathodes. ${ }^{11,12}$ In these contexts, $\mathrm{O}_{2}$ was treated either as a species with the propensity to interfere with other impurities (e.g. by oxidizing poisoning sulfide ions), ${ }^{11}$ or as a catalyst oxidant. ${ }^{12}$ Ex situ catalyst characterization and changes in bulk product distribution were the primary metrics of the impurities' effects, whereas impacts on the electroreduction mechanisms occurring in the cell and the physical phenomena governing the feed impurities' behavior in these contexts were not explicitly treated. Thus, there is a need to build upon these efforts in order to ensure the catalysts being developed for $\mathrm{CO}_{2}$ reduction today will be viable for implementation in the future.

In particular, an abundant and reactive impurity in most anticipated $\mathrm{CO}_{2}$ feed streams is molecular oxygen $\left(\mathrm{O}_{2}\right)$. Oxygentolerant catalytic networks are increasingly being studied for hydrogen evolution; methods for minimizing $\mathrm{O}_{2}$ competition include the development of bio-inspired catalytic pockets in order to exclude, photo-reduce, or otherwise steer molecular oxygen away from poisoning catalytic systems for proton reduction. ${ }^{13}$ Platinum catalysts for the hydrogen evolution reaction (HER) seem to maintain current density to HER in the presence of 0.21 atm $\mathrm{O}_{2} ;{ }^{13}$ however, the exact means by which this is possible have not been investigated. It is equally as important, if not more so, for the impact of $\mathrm{O}_{2}$ on $\mathrm{CO}_{2}$ reduction to be studied and mitigated, since $\mathrm{O}_{2}$ may very well be a constituent of $\mathrm{CO}_{2}$ reduction gas feeds.

The goal of the present work is to demonstrate the effects of the presence of oxygen on the network of reactions occurring during electrochemical $\mathrm{CO}_{2}$ reduction on gold catalysts. Gold was chosen as a test catalyst due to its high activity toward $\mathrm{CO}_{2}$ reduction and for ease of study due to its high selectivity toward only gas-phase products ( $\mathrm{CO}$ and $\left.\mathrm{H}_{2}\right)^{2,4,14-18}$ Cultivating an understanding of oxygen's effect on such an electrocatalytic system will pave the way for the development of systems with tolerance toward a broader variety of gas-phase impurities characteristic of many $\mathrm{CO}_{2}$ point sources, which may be required for industrially viable $\mathrm{CO}_{2}$ reduction.

\section{Results and discussion}

\section{Materials and methods}

Electrochemical cell. A two-compartment cell design was used for $\mathrm{CO}_{2}$ reduction experiments (Fig. S1 $\dagger$ ). ${ }^{19} \mathrm{~A}$ full treatment of cell design and assembly can be found in the ESI (Sections S.2 and S.7†).

Catalyst, electrolyte, reference, and gas feed preparation. Gold foils were mechanically wet-polished using new 400-grit sandpaper for 3 minutes, sonicated in Milli-Q ${ }^{\circledR}$ water for $3-5$ minutes, and dried with compressed nitrogen gas prior to insertion in the electrochemical cell. Unpolished platinum foil was used as the counter-electrode, and the two electrode compartments were separated by a Selemion ${ }^{\mathrm{TM}}$ AMV anionexchange membrane. Sodium bicarbonate electrolytes were prepared by dissolving sodium carbonate into Milli-Q ${ }^{\circledR}$ water to yield solutions with carbonate molarities of $1 / 2$ the desired bicarbonate molarity, followed by bubbling overnight using instrument-grade $(99.99 \%) \mathrm{CO}_{2}$ to convert the carbonate to bicarbonate. A leak-free $\mathrm{Ag} / \mathrm{AgCl}$ reference electrode was used, and was calibrated to a master $\mathrm{Ag} / \mathrm{AgCl}$ reference in saturated $\mathrm{KCl}$ before each experiment. Gas feeds during experiments were mixed by combining research-grade $(99.999 \%) \mathrm{CO}_{2}$, industrialgrade $(99.7 \%) \mathrm{O}_{2}$, and house-supplied $\mathrm{N}_{2}$ (the inert feed) in the appropriate ratios. Total gas flow was set to $10 \mathrm{sccm}$ unless otherwise noted, and the pressure in the electrochemical cell remained at roughly $1 \mathrm{~atm}$. Further details on materials and experiments can be found in ESI (Section S.7†).

Product characterization. While minor electroreduction products were detected through a combination of NMR spectroscopy and colorimetric assays (Section S.8†), the majority of confirmed products were detected through in-line gas chromatography (GC). An SRI MG \#5 Model 8610C GC was set up to auto-sample gas effluent from the electrochemical cell during operation. Products were detected using both a flame ionization detector (FID) and a thermal conductivity detector (TCD). Full details of GC setup and calibration can be found in ESI (Section S. $8 \dagger$ ). GC samples taken at $t=20,30$, and 40 minutes during each electrolysis experiment were averaged for the data reported herein. Oxygen reduction reaction (ORR) current densities for most experiments were calculated from the balance of current after accounting for all detected products. The validity of this approach is confirmed both by lack of detectable liquid-phase products (Section S.8.2†) and by FE closure to $100 \%$ in the absence of oxygen.

\section{Oxygen's effect on reactions in a $\mathrm{CO}_{2} \mathrm{RR}$ cell}

Initial experiments were conducted holding the partial pressure of $\mathrm{CO}_{2}$ constant at $0.5 \mathrm{~atm}$, while the pressure of $\mathrm{O}_{2}$ was varied between 0 and $0.5 \mathrm{~atm}$ using $\mathrm{N}_{2}$ as the balance. The effect of the oxygen partial pressure on partial current densities toward $\mathrm{CO}_{2} \mathrm{RR}$, HER, and ORR was quantified (Fig. 1). Results of this experiment conducted at different voltages can be found in ESI (Section S.9†).

As increasing amounts of oxygen were added to the gas feed, current toward ORR increased linearly while partial currents toward $\mathrm{CO}_{2} \mathrm{RR}$ and HER remained roughly constant. This implies that ORR chemistry did not affect $\mathrm{CO}_{2} \mathrm{RR}$ or HER catalysis. Further, it suggests the nature of the catalyst itself may have been unaffected by the presence of oxygen. It should be noted that there is somewhat larger uncertainty in the partial current measurements toward $\mathrm{CO}_{2} \mathrm{RR}$ and HER, consistent with previous studies using foil electrodes. ${ }^{20,21}$ This is because foil preparation by polishing introduces surface irregularities that cannot be easily replicated from run to run. However, the uncertainties expressed in the error bars of this figure are noticeably small for the ORR data points. This is indicative that 


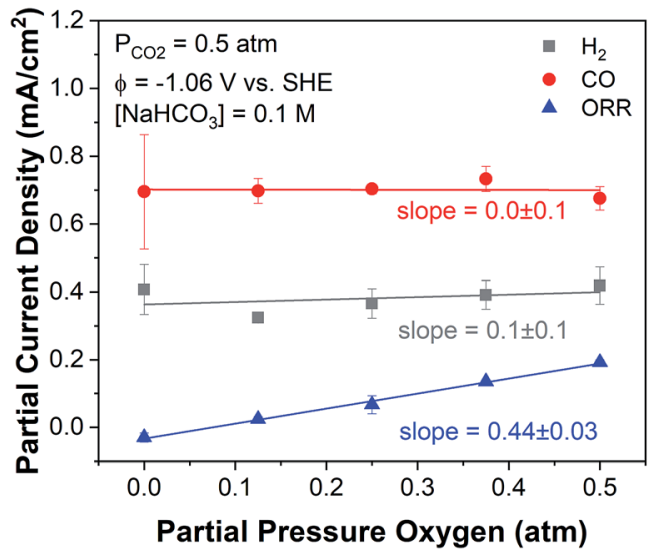

Fig. 1 Oxygen's effect on partial current densities of HER (black), $\mathrm{CO}_{2} \mathrm{RR}$ (red), and ORR (blue) in a cell flowing $0.5 \mathrm{~atm} \mathrm{CO}_{2}$ and various amounts of $\mathrm{O}_{2}$, with $\mathrm{N}_{2}$ as inert balance. Experiments were conducted at $-1.06 \mathrm{~V}$ vs. SHE ( $-0.65 \mathrm{~V}$ vs. $\mathrm{RHE}$ ) in $0.1 \mathrm{M} \mathrm{NaHCO}_{3}$, with each point in duplicate.

the quality of the foil preparation has no effect on ORR currents, and reinforces our confidence in the data.

At less reductive potentials and lower current densities, an apparent negative trend in both $\mathrm{CO}_{2} \mathrm{RR}$ and HER current is observed (Fig. S11†). The fact that this trend is evident only at low overpotentials suggests either that oxygen interferes with these mechanisms in a distinct way at lower overpotentials, or that the effect of $\mathrm{O}_{2}$ in the system is constant, but kept small on an absolute scale, therefore only showing up at low current densities.

To investigate why these trends hold true, the factors governing each reaction - namely, the kinetic versus transport control of ORR, as well as mechanistic aspects of $\mathrm{CO}_{2} \mathrm{RR}$ and HER - were studied in the context of $P_{\mathrm{CO}_{2}}=0.5 \mathrm{~atm}$.

\section{ORR under $\mathrm{CO}_{2}$ reduction conditions on gold}

$\mathrm{CO}_{2} \mathrm{RR}, \mathrm{HER}$, and ORR can be described through the following respective equilibria on gold at $\mathrm{pH} 7:^{2,22}$

$\mathrm{CO}_{2} \mathrm{RR}\left(E^{0}=-0.52 \mathrm{~V} v s\right.$. SHE):

$$
\mathrm{CO}_{2}(\mathrm{aq})+\mathrm{H}_{2} \mathrm{O}(l)+2 \mathrm{e}^{-} \rightleftharpoons \mathrm{CO}(\mathrm{g})+2 \mathrm{OH}^{-}(\mathrm{aq})
$$

$\operatorname{HER}\left(E^{0}=-0.41 \mathrm{~V} v s . \mathrm{SHE}\right)$ :

$$
2 \mathrm{H}_{2} \mathrm{O}(\mathrm{l})+2 \mathrm{e}^{-} \rightleftharpoons \mathrm{H}_{2}(\mathrm{~g})+2 \mathrm{OH}^{-}(\mathrm{aq})
$$

$4 \mathrm{e}^{-}$ORR $\left(E^{0}=0.82 \mathrm{~V} v\right.$ s. SHE):

$$
\mathrm{O}_{2}(\mathrm{aq})+2 \mathrm{H}_{2} \mathrm{O}(\mathrm{l})+4 \mathrm{e}^{-} \rightleftharpoons 4 \mathrm{OH}^{-}(\mathrm{aq})
$$

$2 \mathrm{e}^{-}$ORR $\left(E^{0}=0.28 \mathrm{~V} v s . \mathrm{SHE}\right)$ :

$$
\mathrm{O}_{2}(\mathrm{aq})+2 \mathrm{H}_{2} \mathrm{O}(\mathrm{l})+2 \mathrm{e}^{-} \rightleftharpoons \mathrm{H}_{2} \mathrm{O}_{2}(\mathrm{l})+2 \mathrm{OH}^{-}(\mathrm{aq})
$$

Thermodynamics would dictate that at $\mathrm{CO}_{2}$ reduction conditions that allow for the formation of $\mathrm{CO}$, reducing oxygen is extremely favorable. Since the equilibrium potential for $\mathrm{CO}_{2}$ reduction is roughly $-0.52 \mathrm{~V} v$ s. SHE in neutral media, the cathode must be held at more reductive potentials than $-0.52 \mathrm{~V}$ $v s$. SHE in order to achieve significant $\mathrm{CO}_{2}$ reduction currents. It is reasonable to imagine that at greater than $1.3 \mathrm{~V}$ of overpotential, the rate of ORR may not be strictly dictated by kinetics. However, it was prudent to confirm this experimentally.

In this vein, cyclic voltammograms taken at $P_{\mathrm{CO}_{2}}=0.5 \mathrm{~atm}$ were compared with and without a half-atmosphere of oxygen (Fig. 2A). It can be observed that at around $0.25 \mathrm{~V} v s$. SHE, the onset of ORR occurs. This reduction current density plateaus at $-0.26 \mathrm{~mA} \mathrm{~cm}{ }^{-2}$ around $-0.2 \mathrm{~V} v$ s. SHE. HER and $\mathrm{CO}_{2} \mathrm{RR}$ onset, meanwhile, do not occur until the potential is swept down to almost $-0.8 \mathrm{~V} v s$. SHE. It is therefore concluded from this plot that ORR is transport-limited at the $\mathrm{CO}_{2} \mathrm{RR}$ potentials of interest. This explains the phenomenon wherein ORR current is not impacted by changes introduced to the catalyst surface by polishing - the current is limited by diffusion.

For a planar electrode, assuming a stagnant boundary layer model (Fig. 2B), the formation of a linear species concentration profile at the catalyst surface leads to the expression: ${ }^{23}$

$$
i_{\lim , j}=-\frac{n F D_{j} c_{\text {bulk }, j}}{\delta_{j}}
$$

where $i_{\lim , j}$ represents the diffusion-limited current density for a reduction reaction involving species $j, n$ is the number of electrons involved in the reduction, $F$ is Faraday's constant, $D_{j}$ is the diffusivity of species $j, c_{\text {bulk }, j}$ is the concentration of species $j$ in the bulk of the solution (in turn dictated by Henry's law in the dilute limit), and $\delta_{j}$ is the mass transfer boundary layer thickness for species $j$. Because of the relative insolubility of oxygen in water - the Henry's law constant for $\mathrm{O}_{2}$ is $0.0013 \mathrm{~mol}$ per $\mathrm{kg}$ per bar, compared to $0.034 \mathrm{~mol}$ per $\mathrm{kg}$ per bar for $\mathrm{CO}_{2}{ }^{24}$ - the relative transport-limited current density of oxygen compared to carbon dioxide reduction in solution is quite low.
A

A

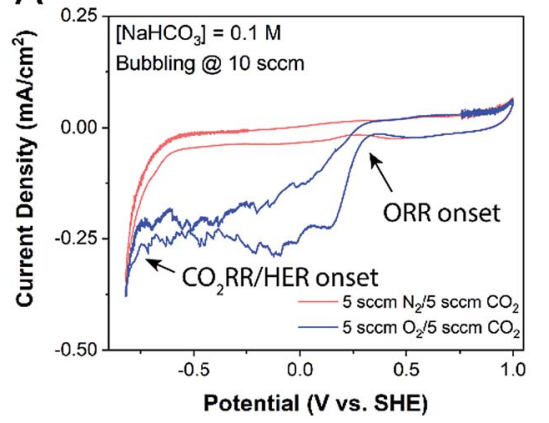

B

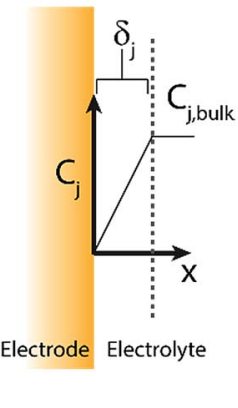

Fig. 2 (A) Modified CV scans (each is cycle \#2 at a scan rate of $20 \mathrm{mV}$ $\mathrm{s}^{-1}$ ) showing the onset and transport limitation of ORR at potentials less reductive than the $\mathrm{CO}_{2} \mathrm{RR}$ operating regime. Relevant transport conditions were simulated by maintaining gas bubbling at $10 \mathrm{sccm}$. (B) Conceptual sketch of the stagnant mass-transport boundary layer model. 
To understand more about the mass-transport boundary layer in the cell, its thickness was determined by measuring the diffusion-limited current density of the ferricyanide ion and back-calculating its mass-transport boundary layer thickness using eqn (1). ${ }^{25} \mathrm{~A}$ conversion was then applied to account for the difference in the diffusion coefficients of ferricyanide and gasphase species such as $\mathrm{CO}_{2}$ and $\mathrm{O}_{2}$ (see ESI Section S.7.5†). For the transport of dissolved $\mathrm{O}_{2}$ gas, the calculated boundary layer thickness was $200 \pm 7 \mu \mathrm{m}$. Using the values $n=4$ (see below), $D_{\mathrm{O}_{2}}=2.10 \times 10^{-5} \mathrm{~cm}^{2} \mathrm{~s}^{-1},{ }^{26}$ and $C_{\text {bulk, } \mathrm{O}_{2}}=0.65 \mathrm{mM}$ at 0.5 atm, ${ }^{24}$ the resulting prediction for the ORR diffusion-limited current density is $0.26 \pm 0.01 \mathrm{~mA} \mathrm{~cm}{ }^{-2}$, in remarkable agreement with our voltammogram.

In addition, it was necessary to confirm which type of ORR was occurring under $\mathrm{CO}_{2}$ reduction conditions. Gold is a known peroxide-forming ORR catalyst, ${ }^{27}$ more typically implicated in selective $\mathrm{H}_{2} \mathrm{O}_{2}$ formation under acidic conditions, ${ }^{28,29}$ whereas within the bicarbonate mass transport boundary layer, conditions should be slightly basic (up to $\mathrm{pH}$ 9-10, depending on the current density drawn). ${ }^{30}$ Long-term experiments passing over $50 \mathrm{C}$ of charge were conducted in order to study the accumulation of ORR liquid-phase products; the colorimetric assay corresponding to the quantification of hydrogen peroxide in this electrolyte returned negative results, meaning that less than $10 \%$ of the oxygen being reduced is forming hydrogen peroxide (Section S.8.3†). We can therefore posit not only that ORR is transport-limited at relevant testing potentials, but also that it is primarily forming water. As water is the chief component of the electrolyte, the ORR products are not expected to interfere with any other catalytic cycles occurring in the cell.

\section{Changes to mechanism of $\mathrm{CO}_{2}$ reduction}

To follow up on these observations, it was pertinent to interrogate the effect that oxygen's presence in the $\mathrm{CO}_{2}$ reduction environment had on the HER and $\mathrm{CO}_{2} \mathrm{RR}$ mechanisms, especially in the low-current density regime. As the kinetics of HER were difficult to probe - a kinetically interpretable Tafel slope for HER was never attained, consistent with previous observations ${ }^{\mathbf{1 6}}$ - the focus of this investigation was on the mechanism of $\mathrm{CO}_{2} \mathrm{RR}$. Probing the effect of oxygen in this context necessitates not only the study of the $\mathrm{CO}_{2}$ reduction mechanism under oxygenated conditions, but also the study of the same mechanism at dilute concentrations and with no oxygen present, as most investigations of $\mathrm{CO}_{2}$ reduction to this point have been conducted at $1 \mathrm{~atm}$ of $\mathrm{CO}_{2} \cdot{ }^{15-18,31}$ To this end, a mechanistic study of $\mathrm{CO}_{2}$ reduction was conducted.

Kinetic data were captured through Tafel analysis, bicarbonate dependence, $\mathrm{CO}_{2}$ dependence, and kinetic isotope effect (KIE) experiments. The results are displayed and discussed below (Fig. 3).

Tafel slope. Tafel slopes were measured under $0.5 \mathrm{~atm}$ of $\mathrm{CO}_{2}$ on $\mathrm{Au}$, both with and without $0.5 \mathrm{~atm} \mathrm{O}_{2}$ (Fig. 3A). The Tafel slope for $\mathrm{CO}_{2} \mathrm{RR}$ under the testing conditions without oxygen is $72 \pm 4 \mathrm{mV} \mathrm{dec}^{-1}$, while in the presence of oxygen the slope is 68 $\pm 6 \mathrm{mV} \mathrm{dec}^{-1}$. The results presented are consistent with a theoretical $59 \mathrm{mV} \mathrm{\textrm {dec } ^ { - 1 }}$ Tafel slope. The resulting data were interpreted as being linear at potentials less reductive than $-0.845 \mathrm{~V} v s$. SHE. At potentials more reductive than this value, nonlinearities are observed which may be due to transport effects, mechanistic changes, or non-exponential kinetic response at high overpotentials.

The Tafel slope of $59 \mathrm{mV} \mathrm{dec}^{-1}$ indicates that a chemical step past the initial electron transfer to $\mathrm{CO}_{2}$ is the rate-determining step (RDS) (see ESI Section S.11†). Subsequent experiments were designed to probe what this chemical step might be. Experiments were intended to probe purely the kinetics of the reaction and therefore were primarily conducted in the linear Tafel region - here selected as $300 \mathrm{mV}$ overpotential, or $-0.41 \mathrm{~V}$ vs. RHE in $0.1 \mathrm{M} \mathrm{NaHCO}_{3}(-0.82 \mathrm{~V}$ vs. SHE).

Bicarbonate order dependence. One possibility for the RDS is the transfer of a proton from bicarbonate to the adsorbed $\mathrm{CO}_{2}$ anion radical $\theta_{\mathrm{CO}_{2}}{ }^{-}$- to form $\theta_{\mathrm{COOH}}$ (here $\theta$ is used to denote a surface adsorption site). The most straightforward way to test this RDS possibility is to conduct a bicarbonate order dependence test. This was done by varying the concentration of sodium bicarbonate in the electrolyte while holding the total solution ionic strength constant with sodium perchlorate. Perchlorate was regarded as an innocent bystander ion, while buffers such as phosphate were avoided due to their ability to poison the catalyst surface. ${ }^{17}$ Further, the potential with respect to SHE rather than RHE was held constant, as this voltage is absolute in nature, and therefore represents the activity of the electron in the reaction - a factor which should be held constant when trying to probe the effects of a different reagent on the reaction rate. A full treatment of this topic can be found in the ESI (Section S.11 $\dagger$ ). These tests were performed at $P_{\mathrm{CO}_{2}}=0.5$ atm both with and without oxygen (Fig. 3B). In processing this data, partial current density results were normalized by the solubility of $\mathrm{CO}_{2}$ - this controls for the secondary "salting-out" effect (see Section S.7.2†). ${ }^{18,32}$

While most conceivable $\mathrm{CO}_{2} \mathrm{RR}$ mechanisms consistent with the Tafel data might have either a zeroth- or first-order dependence on bicarbonate, the slope in the bicarbonate plot suggests that $\mathrm{CO}_{2} \mathrm{RR}$ is negatively impacted by increased bicarbonate concentrations. The slope without $\mathrm{O}_{2}$ is $-0.1 \pm 0.2$, while the slope with $\mathrm{O}_{2}$ is $-0.23 \pm 0.05$. This trend is especially true as we approach the solubility limit of sodium bicarbonate at roughly $1.2 \mathrm{M}$ (see Section S.7.2 $\dagger$ ). ${ }^{33}$ Results of the same experiment repeated with potassium bicarbonate, which is of a different purity than and nearly three times as soluble as the sodium salt, are shown in the ESI (Section S.7.2.2†). Because the potassium bicarbonate data yields a fairly clear zero-order dependence on bicarbonate, it is anticipated that the negative slope in the sodium case is the result of a secondary effect and that the reaction order in bicarbonate is 0 .

$\mathrm{CO}_{2}$ order dependence. Experiments probing the effect of $P_{\mathrm{CO}_{2}}$ in the inlet gas on $\mathrm{CO}_{2} \mathrm{RR}$ current were conducted (Fig. 3C). It should be noted that changes in $P_{\mathrm{CO}_{2}}$ corresponded to bulk electrolyte $\mathrm{pH}$ changes; however, since bicarbonate order was found to be 0 , this was regarded as having no convoluting effect on the $\mathrm{CO}_{2}$ order dependence measurement. With slopes of 1.6 \pm 0.2 and $1.2 \pm 0.3$ respectively for the cases with and without oxygen, the reaction order with respect to $\mathrm{CO}_{2}$ can neither be 
A

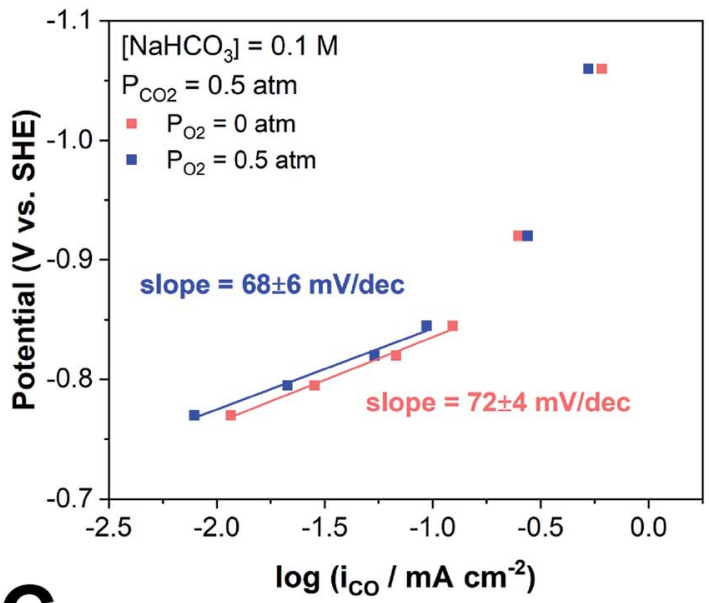

C

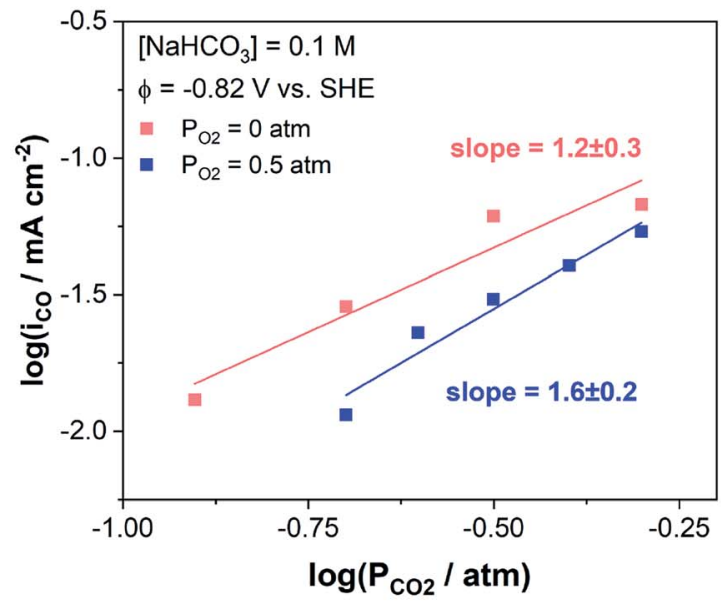

B

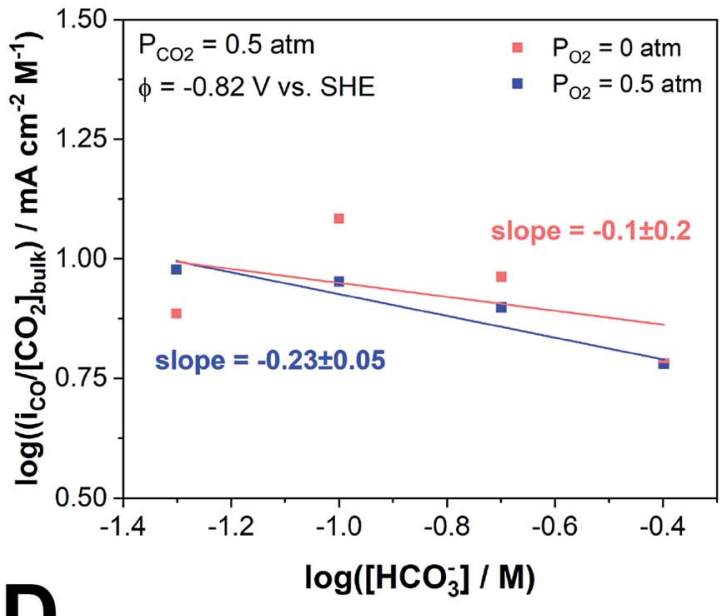

D

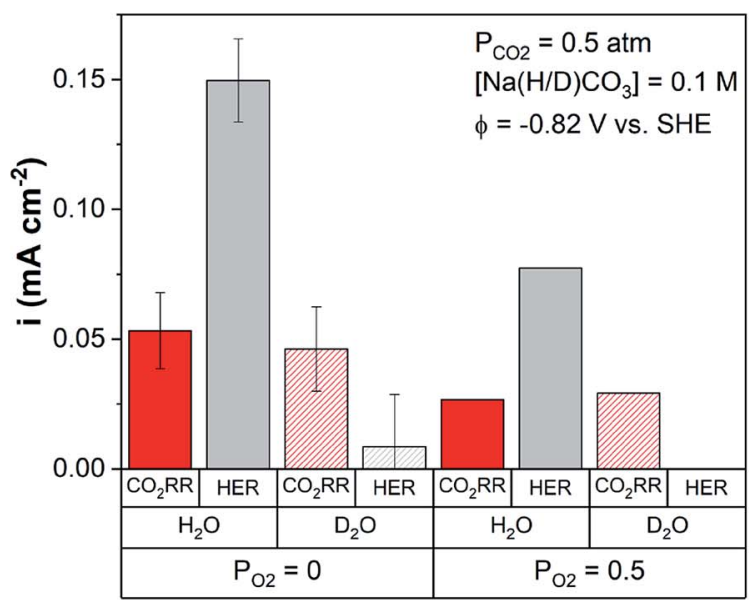

Fig. 3 Summary of $\mathrm{CO}_{2} \mathrm{RR}$ kinetic data on polycrystalline Au for $P_{\mathrm{CO}_{2}}=0.5$ atm, both with and without 0.5 atm $\mathrm{O}_{2}$. (A) Tafel slopes in $0.1 \mathrm{M}$ $\mathrm{NaHCO}_{3}$; (B) bicarbonate dependence at $-0.82 \mathrm{~V}$ vs. SHE normalized by the bulk equilibrium concentration of $\mathrm{CO}_{2}$; (C) $P_{\mathrm{CO}_{2}}$ dependence at $-0.82 \mathrm{~V}$ vs. SHE in $0.1 \mathrm{M} \mathrm{NaHCO}_{3}$; and (D) kinetic isotope effect for HER and $\mathrm{CO}_{2} \mathrm{RR}$ at $-0.82 \mathrm{~V}$ vs. SHE in $0.1 \mathrm{M} \mathrm{Na(H/D)CO}$. Note that, consistent with the $P_{\mathrm{O}_{2}}$ effect data, there is a slight decrease of $\mathrm{CO}_{2} \mathrm{RR}$ and HER currents when oxygen is present.

said to be 1 nor 2 . In fact, it is possible that we are operating in a regime of mixed control, where the rates of different paths toward $\mathrm{CO}_{2}$ reduction - one of which involves a solution-phase $\mathrm{CO}_{2}$ accepting an oxygen atom from a surface-bound species to promote reduction of the bound species - are comparable. From these experiments alone, we cannot entirely rule out the possibility that the activity of $\mathrm{CO}_{2}$ in solution may have a superlinear effect on current densities toward $\mathrm{CO}_{2}$ reduction, although the slope here could also be due to changes in adsorbate coverage and other second-order effects.

Kinetic isotope effect. A proton involved in the RDS of $\mathrm{CO}_{2} \mathrm{RR}$ need not come from the bicarbonate ion; protons are also plentiful in the aqueous solvent. To examine the role of protons in the RDS, it is useful to note that a proton transfer occurring in an RDS is normally subject to a kinetic isotope effect; that is, because the proton is so light, and because its vibrational mode is the coordinate along which the reaction proceeds, affecting the frequency of vibration by swapping out an $\mathrm{H}$ for a $\mathrm{D}$ can elucidate the participation of the $\mathrm{H}$ in the reaction. Thus, experiments were conducted in which the $\mathrm{H}_{2} \mathrm{O}$ solvent was replaced by $\mathrm{D}_{2} \mathrm{O}$, with proper accounting for additional required drying, membrane soaking, and bubbler replacement in order to minimize adventitious $\mathrm{H}_{2} \mathrm{O}$ sources (Fig. 3D) (Section S.7.3†).

It was shown that at the testing conditions, the KIE is negligible ( $\mathrm{KIE}=k_{\mathrm{H}} / k_{\mathrm{D}}=1$ within error) for $\mathrm{CO}_{2}$ reduction, while for HER the value of the KIE is greater than 10. This is suggestive that while the KIE could be considerable in this experiment given the participation of a proton in the RDS, the KIE is not observed, and therefore it is unlikely that a proton transfer is involved. Notably, KIE experiments have been known to lead to false negative conclusions, but only in very specific and rare instances. ${ }^{34}$

Mechanistic interpretation of kinetic data. Notably, the kinetic data obtained here in the context of $P_{\mathrm{CO}_{2}}=0.5 \mathrm{~atm}$ differ from the outcomes presented in existing literature on $\mathrm{CO}_{2} \mathrm{RR}$ mechanisms with $P_{\mathrm{CO}_{2}}=1 \mathrm{~atm} .{ }^{17,18}$ We therefore present a list of 
possible mechanisms, with a focus on those candidates which fit the Tafel slope data (Table 1). Derivations of rate laws and further discussion may be found in ESI (Section S.11†).

In these mechanisms, $\mathrm{CO}_{2} \mathrm{RR}$ is regarded as proceeding through inner-sphere transformations. The mechanistic step $\mathrm{X} .1$, representing an adsorptive electron transfer to $\mathrm{CO}_{2}$, is regarded as the first step in each of the proposed mechanisms. While the list of mechanistic possibilities compiled here is not exhaustive, it encompasses many of the commonly reported mechanisms of $\mathrm{CO}_{2}$ reduction to $\mathrm{CO}$ on $\mathrm{Au}$, as well as a number of speculative possibilities. ${ }^{31}$ In particular, excluded from this list are possibilities involving concerted proton-electron transfer (CPET). However, all mechanisms with CPET corresponding to initial $\mathrm{CO}_{2}$ adsorption can also be collapsed down into the starting points represented by mechanistic steps C.2 and F.2, and therefore are also encompassed by this treatment.

The more commonly accepted intermediates for $\mathrm{CO}_{2} \mathrm{RR}$ are implicated in mechanisms A and B. However, RDS candidates
A. 2 and B. 2 are ruled out due to lack of bicarbonate dependence and KIE, respectively.

If we allow for the participation of surface sites or adsorbed species which are uncommon in the existing literature, then many RDS candidates remain (bolded options, Table 1). These include steps involving the formation of an $\mathrm{Au}-\mathrm{O}$ bond, which we deem unlikely on the basis of gold's low oxophilicity; examples of this are $\theta_{\mathrm{COOH}}$ dissociation into adsorbed $\mathrm{CO}$ and $\mathrm{OH}$ (mechanism $\mathrm{C}$, excluded on the grounds of $\mathrm{pH}$ dependence) and the dissociation of adsorbed $\mathrm{CO}_{2}{ }^{--}$into $\mathrm{CO}$ and an oxygen atom anion radical adsorbate (D.2). Mechanisms forming an $\mathrm{Au}-\mathrm{O}$ bond can be avoided by instead invoking a cationic $\theta_{\mathrm{CO}^{+}}$ adsorbate species, which seems only to have been described in metal complexes rather than on surfaces; $;^{35,36}$ this is exemplified in mechanisms which exhibit the participation of $\mathrm{CO}_{2}$ in the RDS (E.2) and the dissociation of the $\theta_{\mathrm{COOH}}$ intermediate into charged species (mechanism $\mathrm{F}$, excluded on the grounds of $\mathrm{pH}$ dependence). Further, under certain mathematical assumptions and allowing for the $\theta_{\mathrm{COOH}^{-}}$anion, the desorption of $\mathrm{CO}$

Table 1 Postulated mechanisms of $\mathrm{CO}_{2}$ reduction on gold under $0.5 \mathrm{~atm} \mathrm{CO}_{2}{ }^{a_{17,31}}$

\begin{tabular}{|c|c|c|c|c|c|c|}
\hline & RDS & Tafel slope form & $\begin{array}{l}\text { Tafel slope at } \\
298 \mathrm{~K}, \beta=0.5\end{array}$ & Acidic proton order & $P_{\mathrm{CO}_{2}}$ order & KIE? \\
\hline$X .1$ & $\mathrm{CO}_{2}+\theta+e^{-} \rightleftharpoons \theta_{\mathrm{CO}_{2}{ }^{-}}$ & $2.3 R T / \beta F$ & 118 & 0 & 1 & $N$ \\
\hline A. 2 & $\theta_{\mathrm{CO}_{2}}{ }^{--}+\mathrm{HCO}_{3}{ }^{-} \rightleftharpoons \theta_{\mathrm{COOH}}+\mathrm{CO}_{3}{ }^{2-}$ & $2.3 R T / F$ & 59 & 1 & 1 & $\mathrm{Y}$ \\
\hline A. 3 & $\theta_{\mathrm{COOH}}+\mathrm{e}^{-} \rightleftharpoons \theta+\mathrm{CO}+\mathrm{OH}^{-}$ & $2.3 R T /(\beta+1) F$ & 39 & 0 & 1 & $\mathrm{~N}$ \\
\hline C. $2^{*}$ & $\theta_{\mathrm{CO}_{2}}{ }^{--}+\left[\mathrm{H}^{+}\right] \rightleftharpoons \theta_{\mathrm{COOH}}$ & $2.3 R T / F$ & 59 & & 1 & $\mathrm{Y}$ \\
\hline C. 3 & $\theta_{\mathrm{COOH}}+\theta \rightleftharpoons \theta_{\mathrm{CO}}+\theta_{\mathrm{OH}}$ & $2.3 R T / F$ & 59 & 0 & 1 & $\mathrm{~N}$ \\
\hline C. 4 & $\theta_{\mathrm{CO}} \rightleftharpoons \theta+\mathrm{CO}$ & $2.3 R T / 2 F$ & 30 & 0 & 1 & $\mathrm{~N}$ \\
\hline D.2 & 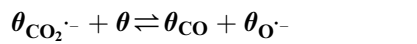 & $2.3 R T / F$ & 59 & $\mathbf{0}$ & 1 & $\mathbf{N}$ \\
\hline E.3 & $\theta_{\mathrm{CO}^{+}}+\mathrm{e}^{-} \rightleftharpoons \theta+\mathrm{CO}$ & $2.3 R T /(\beta+1) F$ & 39 & 0 & 2 & $\mathrm{~N}$ \\
\hline F. $2^{*}$ & $\theta_{\mathrm{CO}_{2}}{ }^{--}+\left[\mathrm{H}^{+}\right] \rightleftharpoons \theta_{\mathrm{COOH}}$ & $2.3 R T / F$ & 59 & & 1 & $\mathrm{Y}$ \\
\hline F.3 & $\theta_{\mathrm{COOH}} \rightleftharpoons \theta_{\mathrm{CO}^{+}}+\mathrm{OH}^{-}$ & $2.3 R T / F$ & 59 & 0 & 1 & $\mathrm{~N}$ \\
\hline F.4 & $\theta_{\mathrm{CO}^{+}}+\mathrm{e}^{-} \rightleftharpoons \theta+\mathrm{CO}$ & $2.3 R T /(\beta+1) F$ & 39 & 0 & 1 & $\mathrm{~N}$ \\
\hline $\mathrm{G} .1^{\dagger}$ & $\mathrm{HCO}_{3}{ }^{-}+\theta+\mathrm{e}^{-} \rightleftharpoons \theta_{\mathrm{H}}+\mathrm{CO}_{3}^{2-}$ & & & & & \\
\hline G.2 & $\theta_{\mathrm{CO}_{2}-{ }^{-}}+\theta_{\mathrm{H}} \rightleftharpoons \theta_{\mathrm{COOH}^{-}}+\theta$ & $2.3 R T / F$ & $59^{*}$ & 0 & 1 & $\mathrm{Y}$ \\
\hline G.3 & $\theta_{\mathrm{COOH}^{-}} \rightleftharpoons \theta+\mathrm{CO}+\mathrm{OH}^{-}$ & $2.3 R T / F$ & $59^{\ddagger}$ & $\mathbf{0}$ & 1 & $\mathbf{N}$ \\
\hline H.2 & 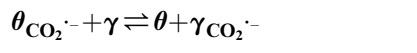 & $2.3 R T / F$ & 59 & $\mathbf{0}$ & 1 & $\mathbf{N}$ \\
\hline
\end{tabular}

${ }^{a}$ Outcomes of experiments to probe the kinetics are listed next to each step in every postulated mechanism, under the circumstances that the step in question is the respective mechanism's rate-determining step (RDS). $\theta$ represents a catalytic active site on the Au electrode. $\beta$ is the symmetry factor, interpreted as being 0.5. X.1 represents the first step in each of the proposed mechanisms. Bolded steps remain plausible RDS candidates after the kinetic investigation conducted here. ${ }^{*} \mathrm{C} .2$ and F.2 are written such that any proton donor could in principle serve as the proton source, including water and bicarbonate. ${ }^{\dagger} \mathrm{G} .1$ is a separate mechanistic step also involved in the HER pathway. ${ }^{\star}$ Mechanism G requires the assumption that $\theta_{\mathrm{H}}$ is dictated by equilibrium described by the Tafel step of HER. See derivation (S.11.4). ${ }^{\diamond}$ H.n steps could in principle be almost anything, including previously listed mechanisms. H.2 is simply the rearrangement of $\mathrm{CO}_{2}{ }^{--}$on the surface to generate an intermediate which then reacts to form products. It does not necessarily require that $\gamma$ differs from $\theta$. 


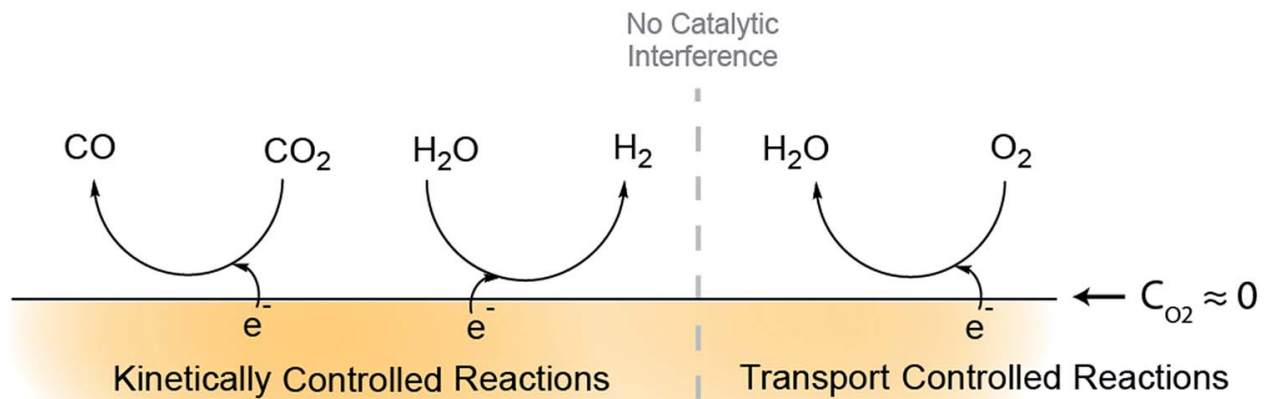

Scheme 1 Interactions between $\mathrm{CO}_{2} \mathrm{RR}$, HER, and ORR during cathodic polarization on a bulk Au surface.

(G.3) is an RDS that is consistent with the data. A conformation change of adsorbed $\mathrm{CO}_{2}{ }^{--}$(H.2) may also serve as the RDS.

Accumulation of surface intermediates involved in these mechanisms could be assessed by use of FT-IR in order to further narrow down the mechanistic possibilities or develop new, more plausible hypotheses. For instance, a large IR band associated with $\theta_{\mathrm{CO}}$ may indicate that this species has accumulated on the surface and is therefore the bottleneck in $\mathrm{CO}_{2} \mathrm{RR}$, supporting a $\mathrm{CO}$ desorption step as an RDS. The observation of such intermediates is currently a subject of debate. ${ }^{16,18}$

More relevant to the discussion of oxygen's effects, however, is the understanding of whether the mechanism of $\mathrm{CO}_{2}$ reduction changes under oxygenated conditions in the electrochemical cell. The findings presented above suggest that so far, we have no reason to believe the mechanism of $\mathrm{CO}_{2}$ reduction changes in the presence of oxygen. This is a promising result if we hope to develop oxygen-tolerant $\mathrm{CO}_{2}$ reduction systems in the future.

\section{Synthesizing the data into a picture of oxygen's interactions}

Our understanding of the effect of ORR on the product distribution allows us to envision the interactions at the catalyst surface wherein the electrocatalytic steps involving $\mathrm{CO}_{2}$ and HER are distinct from and unaffected by ORR intermediates and products (Scheme 1). In this conception of the relevant catalytic interactions, while the mechanisms of none of the individual reactions can be isolated, the chemistries of $\mathrm{CO}_{2} \mathrm{RR}$ and HER $v s$. ORR are nonetheless distinct from one another.

Because oxygen is less soluble than $\mathrm{CO}_{2}$ in aqueous electrolyte, transport provides a protecting effect against ORR. However, that does not mean that ORR even in this context is entirely benign. It is important to note that for practical design purposes, a high-rate $\mathrm{CO}_{2}$ reduction reactor may need to operate under configurations such as a gas diffusion electrode (GDE) or a flowing-electrolyte design, wherein the length scales over which interfacial transport occurs are much smaller, and protecting effects of solubility are lessened. In such a scenario, the mechanistic analysis conducted here may not apply; further, power inefficiencies as a result of ORR may dominate economic considerations. Even in the context of the aqueous cell with a planar electrode reported here, assuming $\mathrm{CO}_{2}: \mathrm{O}_{2}$ ratios typical of flue gas streams from natural gas power plants (roughly $1.67: 1$ ), ${ }^{37}$ and assuming activity and selectivity to $\mathrm{CO}_{2}$ matching those reported here at $-1.06 \mathrm{~V} v s$. SHE, roughly $12 \%$ of applied power would be lost to ORR. In the case that this value in a practical system is smaller than the equivalent power loss required to purify a $\mathrm{CO}_{2}$ stream of oxygen, direct reduction of a mixed $\mathrm{O}_{2} / \mathrm{CO}_{2}$ stream may be a viable design option. The strategy to accept loss of power in a $\mathrm{CO}_{2}$ electrolyzer could be viewed as complementary to other techniques which have been suggested for thermochemically reducing dilute oxygen impurities in $\mathrm{CO}_{2}$-rich feedstocks using methane. ${ }^{38}$

\section{Conclusions}

The presence of oxygen was shown to not have a significant impact on the current toward $\mathrm{CO}_{2}$ reduction at high current densities, largely due to the suppression of ORR by the transport characteristics of a flooded aqueous electrolysis system. The presence of oxygen has not to this point been implicated in affecting the mechanism of $\mathrm{CO}_{2}$ reduction. While these are promising results for $\mathrm{CO}_{2}$ reduction system design and scaleup, it is likely that ORR could become an economic consideration, with the design trade-off being between cost of $\mathrm{CO}_{2}$ separation and power inefficiencies introduced by the presence of oxygen.

Future work should be dedicated toward developing a better understanding of the RDS of $\mathrm{CO}_{2} \mathrm{RR}$ on gold, as well as conducting similar studies on more oxophilic metals. Further, for power efficiency purposes, it may prove economical to invest effort toward the design of an inherently oxygen-tolerant $\mathrm{CO}_{2} \mathrm{RR}$ system through modulating transport parameters at the electrode surface.

\section{Conflicts of interest}

There are no conflicts to declare. 


\section{Acknowledgements}

The authors would like to thank Zachary Schiffer, Kyoungsuk Jin, and Joseph Maalouf for their help and insightful feedback. We also thank the MIT Department of Chemistry Instrumentation Facility (DCIF) for the use of their NMR spectrometer. This work was funded by the MIT Energy Initiative (MITEI) Carbon Capture, Utilization, and Storage (CCUS) Center and the Advanced Concepts Committee at MIT Lincoln Laboratory.

\section{References}

1 I. E. Commission, Electrical Energy Storage, 2011.

2 Y. Hori, Mod. Aspects Electrochem., 2008, vol. 42, pp. 89-189.

3 K. P. Kuhl, E. R. Cave, D. N. Abram and T. F. Jaramillo, Energy Environ. Sci., 2012, 5, 7050-7059.

4 K. P. Kuhl, T. Hatsukade, E. R. Cave, D. N. Abram, J. Kibsgaard and T. F. Jaramillo, J. Am. Chem. Soc., 2014, 136, 14107-14113.

5 H. Kumagai, T. Nishikawa, H. Koizumi, T. Yatsu, G. Sahara, Y. Yamazaki, Y. Tamaki and O. Ishitani, Chem. Sci., 2019, 10, 1597-1606.

6 E. S. R. L. US Department of Commerce, NOAA, ESRL Global Monitoring Division - Global Greenhouse Gas Reference Network, https:/www.esrl.noaa.gov/gmd/ccgg/trends/, accessed 7 November 2018.

7 K. Z. House, A. C. Baclig, M. Ranjan, E. A. van Nierop, J. Wilcox and H. J. Herzog, Proc. Natl. Acad. Sci. U. S. A., 2011, 108, 20428-20433.

8 D. W. Keith, G. Holmes, D. St. Angelo and K. Heidel, Joule, 2018, 2, 1-22.

9 O. S. Bushuyev, P. De Luna, C. T. Dinh, L. Tao, G. Saur, J. Van De Lagemaat, S. O. Kelley and E. H. Sargent, Joule, 2018, 2, 825-832.

10 S. Verma, B. Kim, H. M. Jhong and S. Ma, 2016, 1972-1979.

11 Y. Zhai, L. Chiachiarelli and N. Sridhar, ECS Trans., 2009, 19, 11-13.

12 A. Engelbrecht, M. Hämmerle, R. Moos, M. Fleischer and G. Schmid, Electrochim. Acta, 2017, 224, 642-648.

13 D. W. Wakerley and E. Reisner, Energy Environ. Sci., 2015, 8, 2283-2295.

14 E. R. Cave, J. H. Montoya, K. P. Kuhl, D. N. Abram, T. Hatsukade, C. Shi, C. Hahn, J. K. Nørskov and T. F. Jaramillo, Phys. Chem. Chem. Phys., 2017, 19, 1585615863.

15 Y. Chen, C. W. Li and M. W. Kanan, J. Am. Chem. Soc., 2012, 134, 19969-19972.

16 A. Wuttig, M. Yaguchi, K. Motobayashi, M. Osawa and Y. Surendranath, Proc. Natl. Acad. Sci. U. S. A., 2016, 113, E4585-E4593.

17 A. Wuttig, Y. Yoon, J. Ryu and Y. Surendranath, J. Am. Chem. Soc., 2017, 139, 17109-17113.
18 M. Dunwell, Q. Lu, J. M. Heyes, J. Rosen, J. G. Chen, Y. Yan, F. Jiao and B. Xu, J. Am. Chem. Soc., 2017, 139, 3774-3783.

19 P. Lobaccaro, M. R. Singh, E. L. Clark, Y. Kwon, A. T. Bell and J. W. Ager, Phys. Chem. Chem. Phys., 2016, 18, 26777-26785. 20 T. Hatsukade, K. P. Kuhl, E. R. Cave, D. N. Abram and T. F. Jaramillo, Phys. Chem. Chem. Phys., 2014, 16, 1381413819.

21 A. Wuttig and Y. Surendranath, ACS Catal., 2015, 5, 44794484.

22 Electrochemical Series - Alphabetical Listing, in CRC Handbook of Chemistry and Physics, ed. J. R. Rumble, CRC Press/Taylor \& Francis, Boca Raton, FL, 99th edn, 2018, http://hbcponline.com/faces/documents/05_22/ 05_22_0017.xhtml.

23 W. M. Deen, Analysis of Transport Phenomena, Oxford University Press, 2nd edn, 2011.

24 U. S. D. of Commerce, NIST Chemistry WebBook, 2018, http:// webbook.nist.gov/chemistry/\%0A.

25 E. L. Clark, J. Resasco, A. Landers, J. Lin, L.-T. Chung, A. Walton, C. Hahn, T. F. Jaramillo and A. T. Bell, ACS Catal., 2018, 8, 6560-6570.

26 E. L. Cussler, Diffusion: Mass Transfer in Fluid Systems, 2nd edn, 1997.

27 M. T. M. Koper, Chem. Sci., 2013, 4, 2710-2723.

28 I. Srejić, M. Smiljanić, Z. Rakočević and S. Štrbac, Int. J. Electrochem. Sci., 2016, 11, 10436-10448.

29 X. Ge, A. Sumboja, D. Wuu, T. An, B. Li, F. W. T. Goh, T. S. A. Hor, Y. Zong and Z. Liu, ACS Catal., 2015, 5, 46434667.

30 N. Gupta, M. Gattrell and B. Macdougall, 2006, 161-172.

31 C. W. Lee, N. H. Cho, S. W. Im, M. S. Jee, Y. J. Hwang, B. K. Min and K. T. Nam, J. Mater. Chem. A, 2018, 6, 14043-14057.

32 S. Weisenberger and A. Schumpe, AIChE J., 1996, 42, 298300.

33 N. C. for B. Information, Sodium bicarbonate $\mid \mathrm{NaHCO}_{3}$ PubChem, https://pubchem.ncbi.nlm.nih.gov/compound/ sodium_bicarbonate\#section=Solubility.

34 M. T. Huynh, S. J. Mora, M. Villalba, M. E. Tejeda-Ferrari, P. A. Liddell, B. R. Cherry, A. L. Teillout, C. W. MacHan, C. P. Kubiak, D. Gust, T. A. Moore, S. Hammes-Schiffer and A. L. Moore, ACS Cent. Sci., 2017, 3, 372-380.

35 A. S. Goldman and K. Krogh-Jespersen, J. Am. Chem. Soc., 1996, 118, 12159-12166.

36 Q. Xu, Coord. Chem. Rev., 2002, 231, 83-108.

37 X. Xu, C. Song, R. Wincek, J. M. Andresen, B. G. Miller and A. W. Scaroni, Fuel Chemistry Division Preprints, 2003, 48, 162-163.

38 H. Yang, A. Kuhn, Z. Chen and Y. Lu, Energy Technol., 2018, DOI: $10.1002 /$ ente.201800917. 